\title{
RESENHA
}

\section{WITTMAN, Milton L.; RAMOS, Marília P. (org.), Desenvolvimento regional: Capital social, redes e planejamento. Santa Cruz do Sul: Edunisc, 2004.}

\section{Desenvolvimento regional: Críticas e visões}

O vocábulo "complexo" é um adjetivo que designa algo que contém várias coisas ou ideias, que não é simples, que tem complemento, sendo também entendido como um conjunto de coisas ligadas por nexo comum ${ }^{1}$. A temática do desenvolvimento e mais especificamente a do desenvolvimento das regiões é, na falta de melhor termo para defini-la, complexa. E assim podemos designá-la desde que um determinado pensador afirmou que a questão do desenvolvimento era séria demais para deixar nas mãos apenas dos economistas.

O desenvolvimento regional (DR) é, ao mesmo tempo, processo, problemática, consequência e causa do fenômeno de produção e reprodução da sociedade sobre o espaço geográfico. Como processo, o desenvolvimento regional é entendido como um movimento de mudança das formas de acumulação, nível tecnológico e esquemas de organização social e institucional de cada região em uma nação, sendo entendido como a melhoria nas condições gerais de produção e distribuição objetivada pelos ganhos crescentes das atividades humanas. Este fato indica uma certa progressão entre patamares pré-estabelecidos através de determinados indicadores de renda, produtividade, emprego e qualidade de vida. É problemática por ser um desafio, ao planejamento territorial e às políticas públicas, de promover o desenvolvimento às regiões que objetivamente não passaram por esse processo e, ao mesmo tempo, de manter os níveis de desenvolvimento das regiões econômica e socialmente dinâmicas.

Considerando o princípio do desenvolvimento regional desigual e combinado, como é possível planejar o crescimento das economias locais,

\footnotetext{
${ }^{1}$ Dicionário Priberam de Língua Portuguesa.
} 
com melhorias das condições de vida de suas comunidades, sem afetar a dinâmica das regiões vizinhas? O DR é também a causa da ação do Estado e de agentes privados no sentido de que é produto de pactos e acordos de concertação social, que envolvem interesses específicos de organizações e grupos ideologicamente motivados. Além disso, é consequência, pois, através dos indicadores já citados, as regiões mobilizam suas estruturas políticas, econômicas e sociais visando atingir certos níveis de produção e de "modernização", na concorrência comparativa com outras regiões e, ao atingir ou ultrapassar as metas propostas nos planejamentos regionais, entende-se que o processo produziu consequências previstas ou imprevistas, positivas para alguns e negativas para outros.

Em artigo publicado no ano de $2003^{2}$, o Prof. Francisco de Oliveira afirma que o desenvolvimento local (ou regional, atualmente em voga) é um enigma, pois se refere a uma noção polissêmica. Comporta tantas quantas sejam as dimensões em que se exerce a cidadania e qualquer tentativa, pois, de transformá-lo em modelo paradigmático, está fadada ao fracasso. A cidadania, aproveitando a licença vocabular, é entendida como o conjunto de direitos e deveres ao qual um indivíduo está sujeito em relacão à sociedade em que vive e apresenta, portanto, forte conotacão política e social. Posto isso, se o obietivo do DR também inclui promover melhorias para a população local, é natural pensar que a cidadania e os direitos sociais devem estar atrelados ao planeiamento para as regiões, com insercão fundamental dos governos estaduais e regionais no que tange à distribuicão dos benefícios econômicos advindos com a expansão dos empreendimentos locais e seus segmentos de atividade, garantindo inclusão via acesso à renda, aos serviços básicos e à participação política.

Sérgio Boisier ${ }^{3}$ (2001), sociólogo chileno e especialista na temática do desenvolvimento regional, por seu turno, afirma que o desenvolvimento regional é simultaneamente: um processo de mudança estrutural localizado (em um âmbito territorial denominado "região") e que também alimenta um permanente processo de progresso da própria região, da comunidade ou

${ }^{2}$ OLIVEIRA, F. de. Aproximações ao enigma: Que quer dizer desenvolvimento local? Em SPINK, P.; BAVA, S. C.; PAULICS, V., Novos contornos da gestão local: Conceitos em construção. SP: Pólis/Programa Gestão pública e cidadania, 2002.

${ }^{3}$ BOISIER, S. Desarollo (local). De qué estamos hablando? Em BARQUERO, A. V.; MADOERY, O. (org.), Transformaciones globales, instituciones y políticas de desarollo local. Rosário/ARG: Homo Sapiens, 2001. 
sociedade que a habita e de cada indivíduo membro e habitante de tal território, combinando três dimensões: uma espacial, uma dimensão social e uma individual. A questão espacial remete ao conceito de região e ao seu conteúdo; a dimensão social, à ideia de região como sujeito coletivo e do fortalecimento da sociedade civil e a dimensão individual, a ser pensada através da remoção de barreiras à plena realização da pessoa humana de um membro da comunidade e habitante de cada região.

A afirmação de Oliveira servirá como base de entendimento e de crítica e as dimensões apontadas por Boisier, como metodologia para analisarmos a obra "Desenvolvimento regional: Capital social, redes e planejamento", de 2004, organizada por Milton Luiz Wittman e Marília Patta Ramos, professores da UNISC (Universidade de Santa Cruz do Sul/RS), instituição de perfil comunitário, localizada na parte central do Estado do Rio Grande do Sul. Wittman e Ramos retomam nessa obra os objetivos gerais que permeiam os debates da rede de pesquisa da qual fazem parte, a ESCORE (Estudos setoriais e regionais comparados de diferentes dinâmicas do desenvolvimento regional do RS), discutindo a questão da promoção do desenvolvimento das regiões, com base no exemplo gaúcho dos Conselhos Regionais de Desenvolvimento (COREDES) e exploram três eixos centrais de discussão expostos no título do livro: capital social, redes e planejamento.

$\mathrm{Na}$ apresentação da obra, que aparece como substitutiva à introdução, Bandeira descreve um pouco do quadro de disparidades econômicas e sociais do Rio Grande do Sul e a emergência de um novo regionalismo pautado nas instituições formais e informais, nas características culturais e na composição de redes sociais e econômicas que dão identidade às regiões, ressaltando o papel das Universidades nesse processo. Nesse sentido, os COREDES/RS resgatam a cidadania nas regiões nas quais se estruturam, pois, funcionam como conselhos compósitos por membros da sociedade civil oriundos de diferentes organizações sociais. Em contrapartida, o peso das Universidades na função de atores protagonistas na costura dos "planos de DR" expõe os aspectos de fragilidade das outras instituições locais e regionais (sindicatos, associações, organizações da sociedade civil, cooperativas) na função de forças motrizes do desenvolvimento, ora se fechando nos interesses corporativos e setoriais, ora se colocando como estruturas débeis de representação. A dimensão espacial compreende as regiões do RS; a social é a construção dos COREDES e seus pactos firmados e a individual se reporta às mudanças quantitativas e qualitativas advindas da constituição de novas redes de poder socioterritorial. 
O primeiro capítulo, proposto por Wittman, Dotto e Boff, aborda as formas relacionais de desenvolvimento regional que permeiam a análise da organização empresarial moderna. Desse modo, o texto se inicia com uma discussão sobre a mudança de paradigmas e de modelos organizacionais no capitalismo, a partir do século $\mathrm{XV}$, perpassando pelas revoluções industriais, até chegar ao período da globalização dos mercados e da revolução científico-tecnológica do século XXI. Assim, novas práticas organizacionais e concorrenciais emergem como arquétipo para as empresas. O primeiro modelo comentado foi $\mathbf{0}$ dos aglomerados empresariais, os clusters, reconhecidos como agrupamentos de empresas com os fornecedores, governos e instituições de destaque, podendo também ser tratados na lógica organizacional das redes como ALPs (Arranjos Locais de Produção), SLP (Sistemas Locais de Produção), Sistemas Locais de Inovação e Produção (SLI/P) e o Distritos Industriais (DIs). A segunda parte trata especificamente das estratégias das empresas em redes ou acordos contratuais e acionários no contexto de ascendência da globalização e de novas tecnologias. Assim, a utilização da cooperação empresarial interfere nas estratégias de desenvolvimento regional ao propor novas formas de organização produtiva e de parcerias com governos locais e regionais.

Nesse sentido, a cidadania se revela, nesta leitura, como um subproduto do êxito competitivo das empresas e suas estratégias e alianças, ou seja, o crescimento econômico setorial geraria inclusão social e política. A dimensão espacial se encontra nas diferentes dimensões de territorialização das redes de empresas e do controle político maior ou menor dos níveis regionais e locais de governo sobre as cadeias capitalistas de indústrias e serviços. A dimensão social se expressa nos mercados de emprego e nas instituições públicas e privadas de apoio ou de confronto às empresas que manifestam a ideia de comunidade regional. A dimensão individual e suas satisfações aparecem como resultado da cooperação empresarial e das estratégias coletivas.

O segundo capítulo, de Carlos Paiva, analisa o desenvolvimento capitalista do Rio Grande do Sul através dos conceitos de capital social, comunidade, democracia e planejamento, com aportes teóricos marxistas e de pensadores críticos e desenvolvimentistas, como Florestan Fernandes e Celso Furtado. $\mathrm{O}$ autor analisa historicamente os ciclos de desenvolvimento no RS (a dimensão espacial) e sua condução política e chega à conclusão de que o Estado criou um modelo próprio de acumulação e de regulação (dimensão social) do desenvolvimento capitalista no Brasil, pautado na educação formal, distribuição de terras, 
modernização do sistema logístico e construção de um capital social impregnado no sistema financeiro/bancário e produtivo (dimensões coletivas $e$ individuais). No entanto, esse modelo mostra sinais de esgotamento e necessitaria de um planejamento político voltado à obtenção de altos padrões de sociabilidade e solidariedade (cidadania).

O terceiro capítulo se concentra na reprodução e expansão do desenvolvimento capitalista global no âmbito regional gaúcho, explorando o viés histórico e geográfico do desenvolvimento através do conceito de formação socioespacial. A FSE do Estado sulino apresenta uma dualidade estrutural que concilia a prosperidade econômica para algumas regiões e classes sociais com a exclusão socioeconômica para outras classes e áreas da unidade federativa, dualidade explicada pela crescente modernização agrícola e integração dos minifúndios à agricultura capitalista, com tendências fortes à concentração de capital e oligopolização. A cidadania, neste capítulo, é identificada e localizada, ou seja, não existiria cidadania nas regiões do RS sem haver o caminhar concomitante do dinamismo econômico capitalista com a inclusão social. Tal descompasso verificado em certas localidades expressa uma cidadania raptada ou negada. As dimensões do DR são vistas no elemento espacial pela seleção da unidade federativa e de suas subunidades espaciais internas como elementos de análise. Já a dimensão social é explicada pelo conceito de formação socioespacial, que articula os elementos históricos, sociais e econômicos em eixos de explicação dos processos e dinâmicas territoriais. E a dimensão individual não aparece como força de análise, mostrando-se subentendida pela colocação do termo exclusão social atrelado à ação ou omissão do Estado e do capital, caminho contrário à satisfação de necessidades e oportunidades.

O quarto capítulo, elaborado por Dallabrida, Siedenberg e Fernández, se constitui em uma ampla revisão bibliográfica no sentido de explorar diferentes enfoques analíticos sobre a questão da territorialização do desenvolvimento, debate crescente a partir dos anos 1980. Os autores agrupam as múltiplas abordagens sobre o desenvolvimento em enfoque territorial, em dois eixos centrais de discussão: a vertente globalista e a regionalista. A globalista se pauta na ideia de homogeneização dos espaços locais e na de concorrência perfeita entre localidades, debruçando-se sobre diferentes questões, entre elas, a do city marketing, das cidades-regiões, das estratégias das grandes empresas e de suas unidades produtivas e do esgotamento do Estado-nação. A vertente regionalista se apoia na ideia de que as cidades, as regiões e os territórios têm capacidade de atuar sobre os fatores estruturais que produzem desenvolvimento, em função das próprias 
especificidades do local. Essa linha explora análises sobre organização industrial e inovação, a crise do fordismo, o modelo dos distritos industriais da Terceira Itália e os meios inovadores. Assim, a grande crítica que o artigo faz às abordagens citadas é sobre a aposta contundente, e às vezes otimista, nas capacidades globais (glocalização) e locais (protagonismo e endogenia) de gerar incremento econômico e bem-estar social, sem explicar muito bem como se chegaria a esse processo de produção de benefícios coletivos. Assim, a inovação seria a resposta, tanto nas dimensões organizativas das empresas quanto na organização socioterritorial, sendo que essa última depende tanto do conhecimento socioprodutivo local quanto do conhecimento codificado e filtrado do exterior.

Nesse sentido, a cidadania seria construída ou mobilizada através das inovações nas formas de organização socioterritorial e de sistemas produtivos localizados, que apresentam um forte nível de enraizamento com o meio territorial. A dimensão espacial é a regional, vista como escala territorial de análise, expressão e controle dos movimentos de planejamento e organização da produção e dos complexos socioprodutivos urbanos, rurais e urbanos. A dimensão social é dada pelo conceito de divisão do trabalho localizada e pelas diversas formas de relação, expressas nos modelos analisados, entre empresários e empregados. A dimensão individual é questionada por Dallabrida et al., pois os modelos territoriais de produção sonegam em suas proposições a questão da qualidade de vida e das oportunidades sociais, políticas e culturais, tratando-as como mero produto do êxito econômico das regiões produtoras.

O quinto capítulo de autoria de Dieter R. Siedenberg vai discutir as experiências de desenvolvimento regional no Rio Grande do Sul, tratando especificamente do caso dos Conselhos Regionais de Desenvolvimento (COREDES) à luz dos elementos históricos e políticos de formação do Estado sulino. Os COREDES emergem no cenário político do RS (dimensão espacial) após o advento da Constituição estadual de 1989, que passa a estimular o debate entre governo e sociedade civil (dimensão social) acerca de uma nova regionalização político-administrativa estadual que atuasse no sentido de buscar equidade na distribuição de riqueza entre regiões e integrasse recursos e ações de governo, no sentido de melhorar a qualidade de vida da população (dimensão individual). Em 1994, foram criados 22 COREDES (atualmente são 24), envolvendo experiências e desafios de buscar articular diferentes atores sociais e lideranças políticas, com importante papel de destaque exercido pelas Instituições de Ensino Superior. As principais críticas do autor se dão ao final da análise, quando 
comenta sobre as dificuldades do planejamento endógeno do desenvolvimento regional na atual estrutura federativa brasileira, que apresenta restrições à regulação dos governos estaduais sobre os fatores e processos promotores do desenvolvimento acarretando na concorrência entre Estados para atrair investimentos públicos e privados oriundos de escalas mais amplas (global e nacional). No entanto, ressalta a genuinidade do exemplo dos COREDES para o desenvolvimento econômico e social do RS.

O sexto capítulo tem por objetivo analisar, à luz de aportes teóricos e dos dispositivos legais, a influência da Lei de Responsabilidade Fiscal (LRF) como elemento para o desenvolvimento regional. Seus autores, Marcuzzo, Arend e Ramos, mostram que a LRF remete ao campo de discussões posto no Brasil desde 1990, com as propostas de Reforma do Estado, visando propor alternativas às ditas crises econômica, fiscal e da administração pública e superar o modelo lento, burocrático e formalista de Estado, posto como entrave à sua modernização. A LRF, instituída em âmbito nacional no ano de 2000, tem o duplo objetivo de equilibrar as finanças públicas nos diferentes níveis de governo e estimular a retomada do desenvolvimento, aliando crescimento econômico a melhorias na qualidade de vida da população. Explorando o contexto mundial e nacional de discussão sobre responsabilização/governança política e ajuste fiscal, os autores apontam os principais pilares da LRF para o desenvolvimento, que são: o planejamento, tratando das leis de diretrizes e dos planos plurianuais; a transparência, envolvendo os meios de divulgação e acompanhamento por meio de audiências e instituições como o Tribunal de Contas; o controle, no que tange à qualidade das informações disponibilizadas e dos instrumentos de fiscalização; e por fïm, a responsabilização, que busca promover o cumprimento de regras mediante punições fiscais e penais. Desse modo, os autores reconhecem que a principal influência da LRF sobre o DR ocorre no âmbito dos municípios, abrindo possibilidades quanto à valorização das potencialidades locais e à formação de uma cultura participativa.

Nesse trecho da obra, a cidadania regional se encontra diretamente vinculada à criação de canais de controle e de fiscalização da gestão pública e de sua política fiscal. Esses canais proporcionariam o acesso aos direitos à informação, à transparência e à destinação adequada de recursos públicos necessários ao apoio aos pequenos negócios e à manutenção da ampla rede pública de base às atividades produtivas e não produtivas. A dimensão espacial primaz acentuada é a municipal, o nível local por excelência, e nesse âmbito emergem as problemáticas quanto à 
consolidação do equilíbrio entre planejamento fiscal e justiça social para localidades com pequena autonomia financeira e política. As dimensões social e individual contidas na LRF e a sua eficácia no DR são observadas pela importância dada aos canais de participação política da sociedade civil (Exemplo: Orçamento participativo) e no atendimento às demandas específicas aos direitos sociais mais básicos condicionadas à aplicação correta da receita tributária.

O último capítulo analisa o termo responsabilidade social (RSo) nas empresas e busca entender como essa "nova" postura gerencial influencia os processos de DR. Frey. Frey afirma que a responsabilidade social vem se configurando em uma nova onda de racionalidade, que traz novas concepções de organização das relações entre governo, empresas e sociedade, dando respostas à meta central que seria a de promover o desenvolvimento sustentável. No Estado do RS, em iniciativa pioneira, existe a Lei n. 11.440-00 que institui o Certificado de Responsabilidade Social no âmbito do Estado e que tem servido como instrumento catalisador de ações sociais e programas de participação social no âmbito das empresas, empregados e consumidores. Assim, a RSo inclui elementos variados, ou responsabilidades, que envolvem o campo das ações e medidas filantrópicas, éticas, legais e econômicas, considerando sua incidência no nível local, através de legislações e práticas específicas, que podem contribuir com a mudança da realidade socioterritorial local e aprimorar a cooperação e o diálogo entre iniciativa privada, poder público e comunidade.

A RSo empresarial afeta apenas superficialmente a constituição da cidadania nas regiões, pois determinadas ações filantrópicas de empresas, que poderiam parecer como mitigadoras dos impactos econômicos produtores de segregação social e espacial, no entanto, não interferem nas condições estruturais do capitalismo em globalização e servem apenas como medidas amenizadoras. Quanto às dimensões do DR, a espacial mostrada neste capítulo se refere ao Estado gaúcho e às medidas legais tomadas para controlar politicamente as ações sociais das empresas, concebendo as diretrizes que definem as iniciativas de RSo. A dimensão social é diminuída diante da dimensão individual, que reduz a comunidade regional à sua função social, enquanto trabalhadores participativos nas ações sociais ou consumidores conscientes quanto à qualidade e aos impactos socioambientais dos produtos adquiridos e das empresas produtoras. A dimensão social, coletiva e de forte cunho político, se resume à esfera legal e às concepções genéricas de participação via diálogo e cooperação interinstitucional. 
Ao final da leitura do livro, que já percorreu oito anos de edição, ficam evidentes, ainda, os desafios e as dificuldades de se implementar políticas efetivas de desenvolvimento nas regiões e subunidades regionais do Brasil, considerando a complexidade do tema, pois depende do entrosamento das ferramentas políticas e econômicas de organização da sociedade em seus espaços de vida e reprodução. Ficou-se, assim, com a expectativa de que a obra trouxesse considerações finais que exercitassem uma aproximação entre os seus autores e os diferentes aportes teóricos e conceituais apresentados, além dos exemplos empíricos por eles analisados. Portanto, na ausência de considerações finais gerais, reconhece-se neste compêndio o esforço de trazer enfoques novos a uma discussão que parecia velha e aparentemente "sepultada" nos "escombros" da chamada "Economia urbana e regional". No entanto, ficam ainda muitas perguntas a serem respondidas nos entremeios dessa obra e esses questionamentos decorrem do contraste entre as realidades socioterritoriais de aplicação daqueles modelos e ferramentas de DR descritos e das expectativas, muitas vezes fantásticas e superdimensionadas, que são criadas acerca das potencialidades dos mesmos modelos e ferramentas. Expectativas se afastam crescentemente do sentido prático das dimensões espaciais, sociais e individuais do desenvolvimento e do princípio mais recôndito para a sua realização plena: o resgate da cidadania.

Lucas Labigalini FUINI

Professor Assistente Doutor do Curso de Geografia da Univ. Estadual Paulista/Unesp-Ourinhos. Pesquisador da Fapesp e CNPq. 